\title{
Neurobiochemical Cross-talk Between COVID-19 and Alzheimer's Disease
}

\author{
Mohammad Azizur Rahman ${ }^{1}$ (D) $\cdot$ Kamrul Islam $^{1} \cdot$ Saidur Rahman $^{2} \cdot$ Md Alamin $^{3}$
}

Received: 20 August 2020 / Accepted: 14 October 2020 / Published online: 19 October 2020

(C) The Author(s) 2020

\begin{abstract}
COVID-19, the global threat to humanity, shares etiological cofactors with multiple diseases including Alzheimer's disease (AD). Understanding the common links between COVID-19 and AD would harness strategizing therapeutic approaches against both. Considering the urgency of formulating COVID-19 medication, its AD association and manifestations have been reviewed here, putting emphasis on memory and learning disruption. COVID-19 and AD share common links with respect to angiotensin-converting enzyme 2 (ACE2) receptors and pro-inflammatory markers such as interleukin-1 (IL-1), IL-6, cytoskeleton-associated protein 4 (CKAP4), galectin-9 (GAL-9 or Gal-9), and APOE4 allele. Common etiological factors and common manifestations described in this review would aid in developing therapeutic strategies for both COVID-19 and AD and thus impact on eradicating the ongoing global threat. Thus, people suffering from COVID-19 or who have come round of it as well as people at risk of developing AD or already suffering from AD, would be benefitted.
\end{abstract}

Keywords ACE2 $\cdot$ ApoE4 $\cdot$ Gal-9 $\cdot$ Inflammation $\cdot$ Neuroinvasive

\section{Introduction}

Coronavirus disease 2019 (COVID-19) is caused by severe acute respiratory syndrome coronavirus-2 (SARS-CoV-2) that attacks predominantly the human respiratory system and has also central nervous system (CNS) targeting and neuroinvasive capabilities $[1,2]$. Incubation period of SARS-CoV2 is 5 days, and the mostly noted symptoms of COVID-19 include fever, cough, and fatigue followed by or associated with headache, dyspnea, and hemoptysis [1,2]. Acute respiratory distress syndrome, acute cardiac problems, pneumonia, and multiorgan failure had also been observed in severe cases $[1,2]$. CNS manifestations in about $25 \%$ of

Mohammad Azizur Rahman

azizbmb@juniv.edu

1 Department of Biochemistry and Molecular Biology, Jahangirnagar University, Savar, Dhaka 1342, Bangladesh

2 Department of Chemistry, Jahangirnagar University, Savar, Dhaka 1342, Bangladesh

3 Global Center for Environmental Remediation (GCER), The University of Newcastle, Callaghan, NSW 2308, Australia
COVID-19 patients have been reported [3]. Besides, impaired mental state, delirium, and electrolyte and metabolic derangements have been noticed in some patients [3]. Among central nervous system (CNS) comorbidities of COVID-19, Alzheimer's disease (AD) stands first [4]. AD is a neurodegenerative disorder that affects memory and learning, behavior, and cognitive performance of the patient. The brain region (especially the hippocampus) responsible for memory and learning processes becomes affected due to deposition of amyloid beta $(\mathrm{A} \beta)$ or neurofibrillary tangles (NFT) in the $\mathrm{AD}$ patients [5]. AD symptoms appear mostly after age 60 , and the patients become solely dependent on their caregivers and family members [5]. As COVID-19 management warrants isolation and quarantine, $\mathrm{AD}$ management does not fit with those of COVID-19 [2-4]. Thus, COVID-19 adds extra burden on $\mathrm{AD}$ patients, caregivers, and family members and on the national and global economy. In this regard, identification of common etiological factors would pave new vista in strategizing management and therapeutic approaches against both COVID-19 and AD. Therefore, the present review has been designed to elucidate the common links between COVID-19 and $\mathrm{AD}$ so that scientists, healthcare providers, policy-makers, and the general readers would be benefitted in managing the already sufferers and would also be able in safeguarding the future generation. 


\section{SARS-CoV-2 Invasion and AD-COVID-19 Manifestations}

Possible route of SARS-CoV-2 entry into the human body includes neural parenchyma, the nasal mucosa, the lamina cribrosa, retrograde axonal transport, and the olfactory bulb [6]. The neurotropism characteristic of SARS-CoV-2 aids in its invasion on the neural tissues by binding its spike protein with the angiotensin-converting enzyme 2 (ACE2) receptors present on both neurons and glial cells as well as on the capillary endothelium $[6,7]$. In lungs, epithelium of the upper and lower airways harbor ACE2 mostly $[6,7,8]$. On the other hand, braind stem, capillary endothelium and cardiovascular function regulatory region of the CNS harbor ACE2 highly [6-8]. Compared with those of other SAR-COVs, 10-20-fold increased affinity of SARS-CoV-2 spike protein towards ACE2 has been found [8, 9]. Bypassing the ACE2 receptor, SARS-CoV-2 might utilize the olfactory bulb and avail the trans-synaptic route directly [10, 11]. Upon invasion, SARS-CoV-2 stimulates reactive astrogliosis, microglial activation, and neuroinflammatory cascade. Consequently, the blood-brain barrier (BBB) becomes compromised due to systemic inflammation followed by disrupted brain homeostasis and neuronal death [11]. Subsequent infection of the brain stem might hamper cardiovascular and respiratory regulation through chemosensory neural cells. Deranged ventilator function of the lung aggravates respiratory failure resulting in intense hypoxia [10, 11]. Combined interplay of hypoxia and neuroinflammation destroys the cortical and hippocampal structure and function, resulting in the neurological disorders. According to the direct CNS invasion proposal, SARS-CoV-2 causes inflammatory mediator release leading towards increased BBB permeability and heightened hypoxia [12]. As the CNS is devoid of the major histocompatibility antigen, it becomes solely dependent on cytotoxic $\mathrm{T}$ lymphocytes for removal of virus. Consequently, infectious toxic encephalopathy, acute encephalitis, and cerebrovascular attacks (CVAs) ensue [12]. Headache and seizure are symptoms of acute encephalitis; delirium and coma are symptoms of infectious toxic encephalopathy while an increased risk of CVA is a manifestation of SARS-CoV-2-provoked cytokine storm and coagulation abnormalities [12]. Neuronal expression of ACE2 escalates through nACh receptor stimulation by nicotine, and this makes the smokers much vulnerable towards neuropathological maladies [13].

\section{Concordant Cross-talk Between AD and COVID-19}

\section{Inflammo-proteomics}

Until recently, respiratory syndromes of SARS-COV-2 have got most attention while neurological co-manifestations have received the least though more than one-third of the patients had neurological symptoms [14]. Almost all the neurological symptoms had been manifested during the initial stage of illness [15]. Inflammatory mediators have been implicated in CNS manifestations, and immunological processes in peripheral nervous system (PNS) abnormalities, while skeletal muscle injury has been considered the direct effect of SARS-CoV-2 $[10,16,17]$. Among inflammatory markers, interleukin 6 (IL-6), interleukin 1 (IL-1), cytoskeleton-associated protein 4 (CKAP4), and galectin9 (GAL-9 or Gal-9) had received most attention as the common links between COVID-19 and AD manifestations [18] (Fig. 1).

\section{IL-6}

Plasma level of inflammatory cytokines had been reported to be associated with the status of AD progression and inversely related with immune response [18]. Similarly, human cognitive performance had been inversely linked with chronic peripheral elevation of IL-6 [18]. In line with this, a significantly increased level of plasma IL-6 had been reported in $47 \mathrm{AD}$ patients compared with their age-matched controls [19]. Resultant increased acute-phase proteins in the serum of $\mathrm{AD}$ patients are indicative of compromised immunity. Memory and learning-related behavioral tests (Morris water maze test, hole-board test, elevated plus maze test) on mice revealed that the mice deficient of IL- 6 retain improved reference and spatial memory and demonstrate a better cognitive performance [20]. Though exact mechanism has not been elucidated yet, reduced IL- 6 might mediate a signaling cascade involved in maintaining and restoring memory [20].

An increased serum level of IL-6 had been reported to be linked with increased COVID-19 fatality [21]. A similar trend had been linked for respiratory dysfunction [22, 23]. Plasma proteomics profiling also identified IL- 6 among the most perturbed proteins in COVID-19 patients and marked as an indicator of disease severity [24]. Thus, increased serum IL-6 level is a common indicator of respiratory complications occurred in COVID-19. Also, rapid replication of SARS-CoV-2 triggers elevated production of IL-6 and heightened respiratory distress. Therefore, IL-6 stands as a common biomarker for AD and COVID-19. Antibodies capable of blocking the IL-6 receptor (tocilizumab and sarilumab) have been undergoing phase $2 /$ 3 clinical trials as the putative medications against COVID-19 [25]. As inflammatory process of $\mathrm{AD}$ results in neurodegeneration that could be slowed down through reduced generation of IL-6, tenidap, a non-steroidal anti-inflammatory drug, had been found promising in $\mathrm{AD}$ therapeutics [26]. Thus, IL-6 stands as a pleiotropic biomarker for CNS and respiratory system dysregulation among which $\mathrm{AD}$ and COVID-19 worth mentioning.

\section{IL-1}

IL-1 had been noticed to be significantly higher in the COVID-19 patients during disease onset and entire range of disease progression $[27,28]$. Anakinra, a recombinant IL-1 
Fig. 1 Concordant and disconcordant cross-talk between $\mathrm{AD}$ and COVID-19

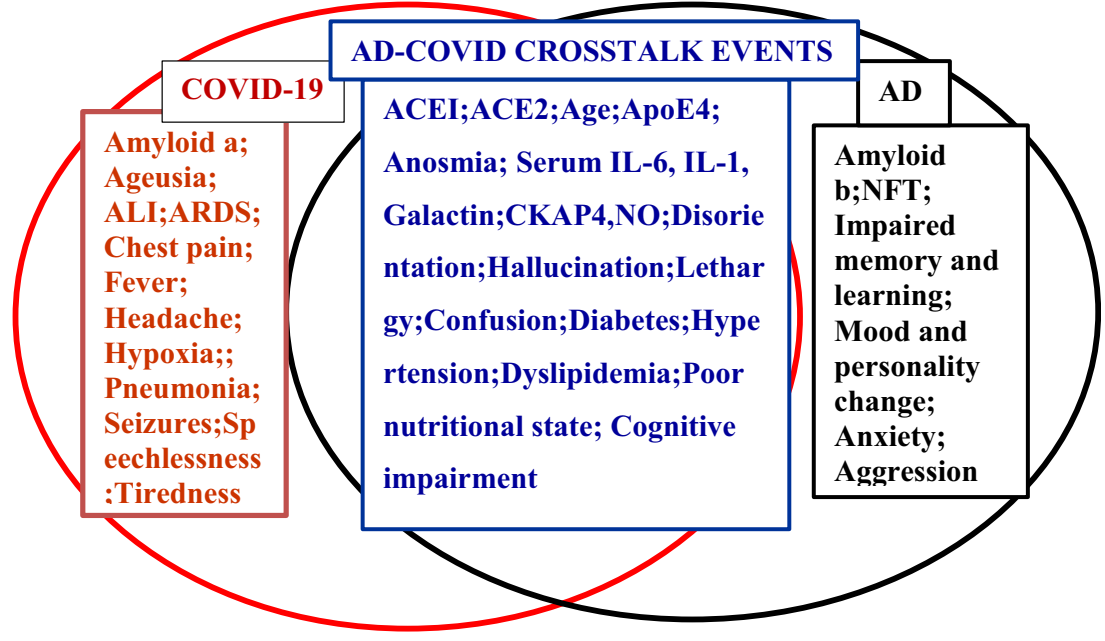

receptor antagonist, had been found effective in improving clinical symptoms especially respiratory distress in $72 \%$ cases [27, 28]. Levels of IL-1 had also been reported to be increased in $\mathrm{AD}$ patients [29]. Impaired long-term potentiation and hippocampal consolidation of memory and learning processes had been associated with increased IL-1 level [30]. Injection of IL- $1 \beta$ in the rat brain showed increased A $\beta$ and NFT production [31]. On the other hand, blockade of IL-1 had been found $\mathrm{AD}$ ameliorating [32].

\section{GAL-9}

Gal-9 is a $\beta$-galactoside-binding protein involved in immune reaction regulation. Its increased production had been associated with viral infection especially in the lung [33]. Thus, therapeutic strategies aimed at suppressing Gal-9 production seem pertinent in COVID-19 pandemic [34]. In the CNS, Gal9 had been reported to be a facilitator of oligodendrocyte maturation and myelin repair mechanism [35]. Increased level of serum Gal-3 had been reported in AD patients [36]. Galectin- 3 had been reported to be a promoter of $A \beta$ oligomerization and toxicity in AD animal models [37]. Thus, galectin-3 is an inflammatory marker whose modulation seems promising in COVID-19 and $\mathrm{AD}$ therapeutics.

\section{CKAP4}

CKAP4, also known as p63, is a 63-kDa, reversibly palmitoylated and phosphorylated, type II transmembrane (TM) protein. CKAP4 regulates the quantity and survival of neuronal precursor cells (NPCs) [38]. Ablation of CKAP4 results in increased NPC death through activation of a proapoptotic p53-PUMA pathway as well as impaired neuronal and hippocampal memory and learning performance [38]. Though CKAP4 involvement in AD pathogenesis has not yet been reported, its role as an NPC pro-survival agent and cognitive enhancer stead this protein as a target in $\mathrm{AD}$ therapeutics [38]. Besides, its role in embryonic development of mammalian CNS has been regarded indispensable [38].

In lungs, CKAP4 had been implicated in maintaining lipid homeostasis through regulation of surfactant turnover [39]. In serum, lung cells, and tissues of the lung cancer patients, CKAP4 had been detected to be significantly higher than those of the healthy controls. Thus, CKAP4 stands as an early serodiagnostic marker for lung cancer and respiratory distress [40]. Plasma proteomics profiling also identified CKAP4 among the most perturbed proteins in COVID-19 patients and marked as an indicator of disease severity [24].

\section{ApoE4 Allele}

Apolipoprotein $\mathrm{E}$ is the main carrier of cholesterol in the central nervous system (CNS) and also an important constituent of very low-density lipoproteins (VLDL). Among its three alleles ( $\varepsilon 2, \varepsilon 3$, and $\varepsilon 4$ ), individuals carrying the $\varepsilon 4$ allele are at a heightened risk of developing $\mathrm{AD}$ as the ApoE $\varepsilon 4 / \varepsilon 4$ genotype increases fibrinogenesis in the brains of Alzheimer's disease patients [41]. ApoE4 has also been reported influencing cerebral hemodynamics such as leakage of the blood-brain barrier and cerebral amyloid angiopathy [41]. Recently, APOE4 has been regarded as a marker increasing COVID-19 severity [42, 43]. Thus, AD patients carrying the APOE4 allele are at a heightened risk of developing COVID-19.

\section{ACE2 Upregulation}

Ten times elevated expression of ACE2 gene, SARS-CoV-2 binding protein for cell entry, had been found in the brain tissues of the AD subjects compared with those of their agematched non-AD individuals [44]. Thus, AD patients are at a heightened risk of COVID-19 comorbidity. 


\section{Nitric Oxide Level}

Nitric oxide (NO), an endothelium-derived relaxing factor and a neurotransmitter, plays an important role in memory and learning process and thus aids in maintaining behavioral and cognitive normalcy [45]. SARS-CoV-2, binding with the vasoconstrictor type 1 angiotensin II receptor (AT1R) through overexpressed ACE2, might lower NO production on cerebral neurons. Consequently, COVID-19 patients would become much vulnerable to behavioral and cognitive decline, the manifestations of $\mathrm{AD}[46]$.

\section{Acetylcholine}

Acetylcholine (Ach) is an excitatory neurotransmitter of the CNS and neuromuscular junction and is essential for neuronal functioning and for memory and learning abilities. According to the cholinergic hypothesis of $\mathrm{AD}$, decreased availability of Ach leads towards AD consequences [47]. Produced by Ach transferase from acetyl-CoA and choline, Ach is released into the synaptic cleft and upon binding to the post-synaptic neuron, exerts signal transduction [47]. Activities of Ach are mediated through two types of receptors, namely, muscarinic and nicotinic [48]. Acetyl choline esterase (AchE) breaks down Ach and does not allow prolonged action of Ach into the post-synaptic neuron, and thus affects memory and learning abilities [47]. AD hallmarks occur due to either structural alterations in cholinergic synapses or alteration of Ach receptors or degeneration of ACh-producing neurons that ultimately lead to deteriorated cholinergic neurotransmission [47]. Therefore, treatment strategies have been developed based on this that agents having anti-AchEI activity would have ameliorating effects on AD [49]. Different AchEIs (donepezil, galantamine, rivastigmine, and tacrine) have been developed to ameliorate AD complications [49]. AchEIs have been reported to improve the cognitive and behavioral performance of the $\mathrm{AD}$ subjects [50].

Ach-mediated lowered production of pro-inflammatory cytokines such as tumor necrosis factor alpha (TNF- $\alpha$ ), IL- $1 \beta$, IL-6, and IL-18 and uninterrupted production of antiinflammatory cytokine IL-10 had been reported [51]. Interestingly, AchEI galantamine had been implicated in lowering TNF- $\alpha$ production [52]. Therefore, inclusion of AchEIs in $\mathrm{AD}$ and COVID-19 therapeutics could lower the production of pro-inflammatory cytokines and aid in antiinflammatory cytokine generation with net result: AD amelioration through Ach make-up and COVID-19 mitigation through pacification of "cytokine storm." Another calming approach to "cytokine storm" is nicotinic receptor-mediated vagus nerve stimulation that yields cholinergic antiinflammatory response $[53,54]$. Thus, treatment strategies applying nicotinic substances and cholinergic system would shed ameliorating influence on both AD and COVID-19 [55].

\section{Degenerated Cholinergic Neurons}

The neurotoxic effect of $A \beta$ oligomers deranges the cholinergic system that manifest in behavioral alteration of AD subjects [56]. Degeneration of the cholinergic neurons up to $75 \%$ in AD brains had been reported [57]. Consequent reduction in ChAT in the hippocampi and cerebral cortex of AD patients had been correlated with degenerated cholinergic nerve endings originated in the basal forebrain and septum [57]. In line with this, inverse relationship between cholinergic neurons with $A \beta$ and NFT generation had been documented in $A D$ animal models [58]. On the other hand, muscarinic receptor agonist or AchEI-based stimulation of the cholinergic receptor systems had been associated with shifting the amyloid precursor protein processing from amyloidogenic towards nonamyloidogenic pathway [59]. In addition to antiinflammatory effects, stimulation of $\alpha 7$ nicotinic receptors had been attributed with neuroprotection against $\mathrm{A} \beta$-, tau-, and NFT-induced neurotoxicity $[60,61]$. Thus, treatment strategies aimed at the cholinergic system aid in amelioration of both $\mathrm{AD}$ and COVID-19.

\section{Anosmia}

Anosmia, the inability of detecting smell or taste, is a hallmark of COVID-19 [62]. Anosmia or its relevant marker hyposmia, lowered sensitivity to detect smell or taste, is also a hallmark of $\mathrm{AD}$ [63]. Anosmia might arise either from infection or blocked nose or due to degeneration of the nasal olfactory receptor neurons [64]. Importantly, brain injury leading to olfactory nerve or system damage may also manifest in anosmia [64]. Recently, a diminished $\mathrm{Zn}^{2+}$ level had been linked with COVID-19 comorbidity of anosmia [65]. SARS-CoV-2induced local deficiency in nasal cellular zinc level might hamper the activity of $\mathrm{Zn}^{2+}$-dependent carbonic anhydrase, the enzyme responsible for olfaction. Immunologically, depleted $\mathrm{Zn}^{2+}$ level might shift the Th1/Th2 balance to Th2 predominance resulting in increased IL- 6 generation of COVID-19 subjects [65]. In this connection, decreased blood $\mathrm{Zn}^{2+}$ level had been associated with $\mathrm{AD}$ [66]. Cognitive impairment associated with olfactory dysfunction had become a common marker of AD and COVID-19.

\section{Discordant Cross-talk Between AD and COVID-19}

Besides the abovementioned similarity-based cross-talks, there exists some disparity-oriented discourse between $\mathrm{AD}$ and COVID-19 [67] (Fig. 1). For example, headache, cough, and seizures are common features of COVID-19 but not of AD [67] (Fig. 1). Some other contrasting features are as follows: 


\section{Age}

Older people are at a higher risk of falling victim of both $\mathrm{AD}$ and COVID-19 [68]. But, for patients aged over 80 years, further aging is not a risk factor for COVID-19, rather for dementia and AD [68]. Though the exact mechanism is not clear yet, reduced susceptibility of secondary lung inflammation might be the cause [68]. On the other hand, AD susceptibility usually begins on or after 60 years of age and as aging advances, so soars the AD pathogenesis [69]. Heightened production of reactive oxygen species (ROS), exacerbated amyloid beta production, aggregation and neurodegeneration, perturbed proteostasis, cardiovascular diseases (CVD), diabetes, hypertension, and lifestyle modification had been implicated in AD pathogenesis of the aged persons [69].

\section{Sex}

Compared with females, males had been found much vulnerable to COVID-19 fatality [70]. Increased ACE2 level, effect of testosterone on ACE2, imbalance among ACE2 products (Ang $1-7$, Ang 1-9), and dire onslaught of cytokine storm are among the possible factors affecting men much than those of the women [70]. Thus, manipulation of ACE2 expression through sex hormone modulators seems pertinent in treating COVID-19. On the other hand, estrogen and testosterone levels had been found neuroprotective and amyloid beta-clearing agents [71]. In female $\mathrm{AD}$ patients older than 80 years, brain levels of androgen and estrogen had been found lower than their agematched non-AD counterparts [72]. In case of normal and $\mathrm{AD}$ male subjects, the downtrend level of androgen and testosterone had been observed as aging progresses over 70 years [ 72 , 73]. Thus, disparity in sex hormone levels contributes to the biased prospect of AD or COVID-19 in men and women. Keeping pace with this fact, treatment strategies might be formulated to restore the sex hormone levels in respective patients.

\section{Different Treatment Strategies}

$\mathrm{AD}$ and COVID-19 differ in their etiology. AD is caused by deposition of abnormally higher levels of $A \beta$ or NFT. Thus, treatment strategies against $\mathrm{AD}$ focus mainly withstanding $\mathrm{A} \beta$ production or accelerating its clearance [74]. On the other hand, COVID-19 is caused by SARS-CoV-2 entry into host cell and subsequent inflammatory, respiratory, cardiovascular, CNS, and psychological complications. Thus, COVID-19 treatment strategies tend to impede viral entry, viral replication, and subsequent symptom amelioration. In this regard, SARS-CoV-2-directed drugs (remdesivir, lopinavir), hosttargeting agents such as ACE/ACE2 receptor inhibitors, angiotensin receptor blockers (ARB), and immunomodulators such as inhibitors to IL-6 and IL-1, and convalescent plasma therapy had been in practice worldwide [75].

\section{Conclusion}

In addition to the persisting COVID-19 complications, its long-term consequences have been shaking the healthcare professionals globally. Alzheimer's disease stands among the top-notch out-turn of COVID-19. Etiological cofactors and physiological co-manifestations described in this review would succor in strategizing therapeutic approaches against both COVID-19 and AD. We must admit that we have depended only upon the data available at hand, and we must look towards future directions from the scientific community to hold back the global crises like COVID-19 and AD.

Authors' Contributions All the authors contributed equally in preparing this manuscript.

Data Availability Not applicable.

\section{Compliance with Ethical Standards}

Conflict of Interest The authors declare that they have no conflicts of interest.

Code Availability Not applicable.

Open Access This article is licensed under a Creative Commons Attribution 4.0 International License, which permits use, sharing, adaptation, distribution and reproduction in any medium or format, as long as you give appropriate credit to the original author(s) and the source, provide a link to the Creative Commons licence, and indicate if changes were made. The images or other third party material in this article are included in the article's Creative Commons licence, unless indicated otherwise in a credit line to the material. If material is not included in the article's Creative Commons licence and your intended use is not permitted by statutory regulation or exceeds the permitted use, you will need to obtain permission directly from the copyright holder. To view a copy of this licence, visit http://creativecommons.org/licenses/by/4.0/.

\section{References}

1. Desforges M, Le Coupanec A, Dubeau P (2019) Human coronaviruses and other respiratory viruses: underestimated opportunistic pathogens of the central nervous system? Viruses 12(1):14. https://doi.org/10.3390/v12010014

2. Asadi-Pooya AA, Simani L (2020) Central nervous system manifestations of COVID-19: a systematic review. J Neurol Sci 413: 116832. https://doi.org/10.1016/j.jns.2020.116832

3. Mao L, Jin H, Wang M (2020) Neurologic manifestations of hospitalized patients with coronavirus disease 2019 in Wuhan, China. JAMA Neurol 77(6):1-9. https://doi.org/10.1001/jamaneurol.2020.1127

4. Fotuhi M, Mian A, Meysami S, Raji CA (2020) Neurobiology of COVID-19. J Alzheimers Dis 76(1):3-19. https://doi.org/10.3233/ JAD-200581

5. Hardy JA, Higgins GA (1992) Alzheimer's disease: the amyloid cascade hypothesis. Science 256(5054):184-185

6. Baig AM, Khaleeq A, Ali U, Syeda H (2020) Evidence of the COVID-19 virus targeting the CNS: tissue distribution, host-virus 
interaction, and proposed neurotropic mechanisms. ACS Chem Neurosci 11(7):995-998

7. Li YC, Bai WZ, Hashikawa T (2020) The neuroinvasive potential of SARS-CoV2 may play a role in the respiratory failure of COVID-19 patients. J Med Virol 92(6):552-555. https://doi.org/ $10.1002 /$ jmv. 25728

8. Wrapp D, Wang N, Corbett KS (2020) Cryo-EM structure of the 2019-nCoV spike in the prefusion conformation. Science 367(6483):1260-1263. https://doi.org/10.1126/science.abb2507

9. Bridwell R, Long B, Gottlieb M (2020) Neurologic complications of COVID-19. Am J Emerg Med 38(7):1549.e3-1549.e7. https:// doi.org/10.1016/j.ajem.2020.05.024

10. Sheraton M, Deo N, Kashyap R (2020) A review of neurological complications of COVID-19. Cureus 12(5):e8192. https://doi.org/ 10.7759 /cureus. 8192

11. Steardo L, Steardo L Jr, Zorec R, Verkhratsky A (2020) Neuroinfection may contribute to pathophysiology and clinical manifestations of COVID-19. Acta Physiol (Oxford) 229(3): e13473. https://doi.org/10.1111/apha.13473

12. $\mathrm{Wu} \mathrm{Y,} \mathrm{Xu} \mathrm{X,} \mathrm{Chen} \mathrm{Z} \mathrm{(2020)} \mathrm{Nervous} \mathrm{system} \mathrm{involvement} \mathrm{after}$ infection with COVID-19 and other coronaviruses. Brain Behav Immun 87:18-22. https://doi.org/10.1016/j.bbi.2020.03.03

13. Kabbani N, Olds JL (2020) Does COVID19 infect the brain? If so, smokers might be at a higher risk. Mol Pharmacol 97(5):351-353. https://doi.org/10.1124/molpharm.120.000014

14. Whittaker A, Anson M, Harky A (2020) Neurological manifestations of COVID-19: a systematic review and current update. Acta Neurol Scand 142(1):14-22. https://doi.org/10.1111/ane.13266

15. Hartung H, Aktas O (2020) COVID-19 and management of neuroimmunological disorders. Nat Rev Neurol 16:347-348. https://doi.org/10.1038/s41582-020-0368-9

16. Varatharaj A, Thomas N, Ellul MA (2020) Neurological and neuropsychiatric complications of COVID-19 in 153 patients: a UKwide surveillance study. Lancet Psychiatry S2215-0366(20): 30287-3028X. https://doi.org/10.1016/S2215-0366(20)30287-X

17. Lahiri D, Ardila A (2020) COVID-19 pandemic: a neurological perspective. Cureus 12(4):e7889. https://doi.org/10.7759/cureus. 7889

18. Cojocaru IM, Cojocaru M, Miu G, Sapira V (2011) Study of interleukin-6 production in Alzheimer's disease. Rom J Intern Med 49(1):55-58

19. Motta M, Imbesi R, Di Rosa M, Stivala F, Malaguarnera L (2007) Altered plasma cytokine levels in Alzheimer's disease: correlation with the disease progression. Immunol Lett 114(1):46-51. https:// doi.org/10.1016/j.imlet.2007.09.002

20. Bialuk I, Taranta A, Winnicka MM (2018) IL-6 deficiency alters spatial memory in 4- and 24-month-old mice. Neurobiol Learn Mem 155:21-29. https://doi.org/10.1016/j.nlm.2018.06.006

21. Chen X, Zhao B, Qu Y, Chen Y (2020) Detectable serum SARSCoV-2 viral load (RNAaemia) is closely correlated with drastically elevated interleukin 6 (IL-6) level in critically ill COVID-19 patients. Clin Infect Dis ciaa449. https://doi.org/10.1093/cid/ciaa449

22. Wang H, Luo S, Shen Y, Li M (2020) Multiple enzyme release, inflammation storm and hypercoagulability are prominent indicators for disease progression in COVID-19: a multi-centered, correlation study with CT imaging score. https://ssrn.com/abstract= 3544837 or https://doi.org/10.2139/ssrn.3544837. Accessed 2 March 2020

23. Ulhaq ZS, Soraya GV (2020) Interleukin-6 as a potential biomarker of COVID-19 progression. Med Mal Infect 50(4):382-383. https:// doi.org/10.1016/j.medmal.2020.04.002

24. Patel H, Ashton NJ, Dobson RJ, Anderson LM (2020) Proteomic blood profiling in mild, severe and critical COVID-19 patients. medRxiv. https://doi.org/10.1101/2020.06.22.20137216

25. Zhang C, Wu Z, Li J-W, Zhao H, Wang G-Q (2020) The cytokine release syndrome (CRS) of severe COVID-19 and interleukin-6 receptor (IL-6R) antagonist tocilizumab may be the key to reduce the mortality. Int J Antimicrob Agents 55(5):105954. https://doi. org/10.1016/j.ijantimicag.2020.105954

26. Hüll M, Fiebich BL, Lieb K, Strauss S (1996) Interleukin-6associated inflammatory processes in Alzheimer's disease: new therapeutic options. Neurobiol Aging 17(5):795-800. https://doi. org/10.1016/0197-4580(96)00107-8

27. Raphaël C, Marie K, David D, Cécile M (2020) Early IL-1 receptor blockade in severe inflammatory respiratory failure complicating COVID-19. PNAS 117(32):18951-18953. https://doi.org/10. 1073/pnas.2009017117

28. Cavalli G, De Luca G, Campochiaro C (2020) Interleukin-1 blockade with high-dose anakinra in patients with COVID-19, acute respiratory distress syndrome, and hyperinflammation: a retrospective cohort study. Lancet Rheumatol 2:e325-e331. https://doi.org/ 10.1016/S2665-9913(20)30127-2

29. Griffin WS, Stanley LC, Ling C, White L (1989) Brain interleukin 1 and S-100 immunoreactivity are elevated in Down syndrome and Alzheimer disease. PNAS 86(19):7611-7615

30. Pugh RC, Fleshner M, Watkins LR, Maier SF, Rudy JW (2001) The immune system and memory consolidation: a role for the cytokine IL-1beta. Neurosci Biobehav Rev 25(1):29-41

31. Sheng JG, Ito K, Skinner RD, Mrak RE, Rovnaghi CR, Van Eldik LJ, Griffin WS (1996) In vivo and in vitro evidence supporting a role for the inflammatory cytokine interleukin-1 as a driving force in Alzheimer pathogenesis. Neurobiol Aging 17(5):761-766

32. Depino AM, Alonso M, Ferrari C, del Rey A, Anthony D (2004) Learning modulation by endogenous hippocampal IL-1: blockade of endogenous IL-1 facilitates memory formation. Hippocampus 14(4):526-535

33. Lu X, McCoy KS, Xu J, Hu W (2015) Galectin-9 ameliorates respiratory syncytial virus-induced pulmonary immunopathology through regulating the balance between Th17 and regulatory $\mathrm{T}$ cells. Virus Res 195:162-171. https://doi.org/10.1016/j.virusres. 2014.10.011

34. Caniglia JL, Guda MR, Asuthkar S (2020) A potential role for galectin-3 inhibitors in the treatment of COVID-19. Peer J 8: e9392. https://doi.org/10.7717/peerj.9392

35. Rinaldi M, Thomas L, Mathieu P, Carabias P (2016) Galectin-1 circumvents lysolecithin-induced demyelination through the modulation of microglial polarization/phagocytosis and oligodendroglial differentiation. Neurobiol Dis 96:127-143

36. Wang X, Zhang S, Lin F, Chu W, Yue S (2015) Elevated galectin-3 levels in the serum of patients with Alzheimer's disease. Am J Alzheimers Dis Other 30(8):729-732. https://doi.org/10.1177/ 1533317513495107

37. Tao CC, Cheng KM, Ma YL, Hsu WL (2020) Galectin-3 promotes $A \beta$ oligomerization and $A \beta$ toxicity in a mouse model of Alzheimer's disease. Cell Death Differ 27(1):192-209. https://doi. org/10.1038/s41418-019-0348-Z

38. Cancino GI, Yiu AP, Fatt MP, Dugani CB (2013) p63 regulates adult neural precursor and newly born neuron survival to control hippocampal-dependent behavior. J Neurosci 33(31):1256912585. https://doi.org/10.1523/JNEUROSCI.1251-13.2013

39. Kazi AS, Tao JQ, Feinstein SI, Zhang L, Fisher AB, Bates SR (2010) Role of the PI3-kinase signaling pathway in trafficking of the surfactant protein A receptor P63 (CKAP4) on type II pneumocytes. Am J Physiol Lung Cell Mol Physiol 299(6):L794 L807. https://doi.org/10.1152/ajplung.00372.2009

40. Yanagita K, Nagashio R, Jiang SX, Kuchitsu Y (2018) Cytoskeleton-associated protein 4 is a novel serodiagnostic marker for lung cancer. Am J Pathol 188(6):1328-1333. https://doi.org/10. 1016/j.ajpath.2018.03.007

41. Hultman K, Strickland S, Norris EH (2013) The APOE $\varepsilon 4 / \varepsilon 4$ genotype potentiates vascular fibrin(ogen) deposition in amyloid- 
laden vessels in the brains of Alzheimer's disease patients. J Cereb Blood Flow Metab 33(8):1251-1258

42. Beeri MS, Rapp M, Silverman JM, Schmeidler J (2006) Coronary artery disease is associated with Alzheimer disease neuropathology in APOE4 carriers. Neurology 66(9):1399-1404. https://doi.org/10. 1212/01.wnl.0000210447.19748.0b

43. Kuo CL, Pilling LC, Atkins JL, Masoli J (2020) APOEe4 genotype predicts severe COVID-19 in the UK Biobank community cohort. J Gerontol A Biol Sci Med Sci glaa131:2231-2232. https://doi.org/ 10.1093/gerona/glaa131

44. Lim KH, Yang S, Kim SH, Joo JY (2020) Elevation of ACE2 as a SARS-CoV-2 entry receptor gene expression in Alzheimer's disease. J Inf Secur 81(3):e33-e34. https://doi.org/10.1016/j.jinf.2020. 06.072

45. Susswein AJ, Katzoff A, Miller N, Hurwitz I (2004) Nitric oxide and memory. Neuroscientist 10:153-162

46. Alkeridy WA, Almaghlouth I, Alrashed R (2020) A unique presentation of delirium in a patient with otherwise asymptomatic COVID-19. J Am Geriatr Soc 10:1111-1384. https://doi.org/10. 1111/jgs. 16536

47. Stanciu GD, Luca A, Rusu RN (2019) Alzheimer's disease pharmacotherapy in relation to cholinergic system involvement. Biomolecules 10(1):40. Published 2019 Dec 26. https://doi.org/ 10.3390/biom10010040

48. Farhat SM, Ahmed T (2017) Neuroprotective and neurotoxic implications of $\alpha 7$ nicotinic acetylcholine receptor and $A \beta$ interaction: therapeutic options in Alzheimer's disease. Curr Drug Targets 18(13): 1537-1544. https://doi.org/10.2174/1389450117666161005145143

49. Sharma K (2019) Cholinesterase inhibitors as Alzheimer's therapeutics (review). Mol Med Rep 20(2):1479-1487. https://doi.org/ 10.3892/mmr.2019.10374

50. Hampel H, Mesulam MM, Cuello AC (2019) Revisiting the cholinergic hypothesis in Alzheimer's disease: emerging evidence from translational and clinical research. J Prev Alzheimers Dis 6(1):2-15. https://doi.org/10.14283/jpad.2018.43

51. Hoover DB (2017) Cholinergic modulation of the immune system presents new approaches for treating inflammation. Pharmacol Ther 179:1-16. https://doi.org/10.1016/j.pharmthera.2017.05.002

52. Gowayed MA, Refaat R, Ahmed WM, El-Abhar HS (2015) Effect of galantamine on adjuvant-induced arthritis in rats. Eur $\mathrm{J}$ Pharmacol 764:547-553

53. Ulloa L (2005) The vagus nerve and the nicotinic anti-inflammatory pathway. Nat Rev Drug Discov 4:673-684

54. Changeux JP, Amoura Z, Rey FA, Miyara M (2020) A nicotinic hypothesis for Covid-19 with preventive and therapeutic implications. C R Biol 343(1):33-39. Published 2020 Jun 5. https://doi.org/ $10.5802 /$ crbiol.8

55. Farsalinos K, Niaura R, Le Houezec J, Barbouni A, Tsatsakis A, Kouretas D, Vantarakis A, Poulas K (2020) Editorial: nicotine and SARS-CoV-2: COVID-19 may be a disease of the nicotinic cholinergic system. Toxicol Rep 7:658-663

56. Ferreira-Vieira TH, Guimaraes IM, Silva FR, Ribeiro FM (2016) Alzheimer's disease: targeting the cholinergic system. Curr Neuropharmacol 14(1):101-115. https://doi.org/10.2174/ 1570159x13666150716165726

57. Whitehouse PJ, Price DL, Struble RG, Clark AW, Coyle JT, Delon MR (1982) Alzheimer's disease and senile dementia: loss of neurons in the basal forebrain. Science. 215:1237-1239. https://doi. org/10.1126/science. 7058341

58. Ramos-Rodriguez JJ, Pacheco-Herrero M, Thyssen D, MurilloCarretero MI, Berrocoso E, Spires-Jones TL (2013) Rapid bamyloid deposition and cognitive impairment after cholinergic denervation in APP/PS1 mice. J Neuropathol Exp Neurol 72:272-285
59. Mori F, Lai CC, Fusi F, Giacobini E (1995) Cholinesterase inhibitors increase secretion of APPs in rat brain cortex. Neuroreport 6: 633-636

60. Hampel H, Mesulam MM, Cuello AC (2018) The cholinergic system in the pathophysiology and treatment of Alzheimer's disease. Brain. 141(7):1917-1933. https://doi.org/10.1093/brain/awy132

61. Naughton SX, Raval U, Pasinetti GM (2020) Potential novel role of COVID-19 in Alzheimer's disease and preventative mitigation strategies. J Alzheimers Dis 76(1):21-25. https://doi.org/10.3233/ JAD-200537

62. Moein ST, Hashemian SM, Mansourafshar B, Khorram-Tousi A, Tabarsi P, Doty RL (2020) Smell dysfunction: a biomarker for COVID-19. Int Forum Allergy Rhinol 10(8):944-950. https://doi. org/10.1002/alr.22587

63. Burns A (2000) Might olfactory dysfunction be a marker of early Alzheimer's disease? Lancet. 355:84-85

64. Han AY, Mukdad L, Long JL, Lopez IA (2020) Anosmia in COVID-19: mechanisms and significance. Chem Senses 45(6): 423-428. https://doi.org/10.1093/chemse/bjaa040

65. Equils O, Lekaj K, Fattani S, Wu A, Liu G (2020) Proposed mechanism for anosmia during COVID-19: the role of local zinc distribution. J Translan Sci 7:1-2. https://doi.org/10.15761/JTS.1000397

66. Brewer GJ, Kanzer SH, Zimmerman EA, Molho ES, Celmins DF, Heckman SM, Dick R (2010) Subclinical zinc deficiency in Alzheimer's disease and Parkinson's disease. Am J Alzheimers Dis Other Dement 25(7):572-575. https://doi.org/10.1177/ 1533317510382283

67. Gold MS, Sehayek D, Gabrielli S, Zhang X, McCusker C, BenShoshan M (2020) COVID-19 and comorbidities: a systematic review and meta-analysis [published online ahead of print, 2020 Jul 14]. Postgrad Med:1-7. https://doi.org/10.1080/00325481. 2020.1786964

68. Covino M, De Matteis G, Santoro M et al (2020) Clinical characteristics and prognostic factors in COVID-19 patients aged $\geq 80$ years. Geriatr Gerontol Int 20(7):704-708. https://doi.org/10. 1111/ggi.13960

69. Xia X, Jiang Q, McDermott J, Han JJ (2018) Aging and Alzheimer's disease: comparison and associations from molecular to system level. Aging Cell 17(5):e12802. https://doi.org/10.1111/ acel.12802

70. Maleki Dana P, Sadoughi F, Hallajzadeh J, Asemi Z, Mansournia MA, Yousefi B, Momen-Heravi M (2020) An insight into the sex differences in COVID-19 patients: what are the possible causes? Prehosp Disaster Med 35(4):438-441. https://doi.org/10.1017/ S1049023X20000837

71. Elgendy IY, Pepine CJ (2020) Why are women better protected from COVID-19: clues for men? Sex and COVID-19. Int J Cardiol 315:105-106. https://doi.org/10.1016/j.ijcard.2020.05.026

72. Pike CJ (2017) Sex and the development of Alzheimer's disease. J Neurosci Res 95(1-2):671-680. https://doi.org/10.1002/jnr.23827

73. Mielke MM, Ferretti MT, Iulita MF, Hayden K, Khachaturian AS (2018) Sex and gender in Alzheimer's disease - does it matter? Alzheimers Dement 14(9):1101-1103. https://doi.org/10.1016/j. jalz.2018.08.003

74. Lane CA, Hardy J, Schott JM (2018) Alzheimer's disease. Eur J Neurol 25(1):59-70. https://doi.org/10.1111/ene.13439

75. Jamshaid H, Zahid F, Din IU et al (2020) Diagnostic and treatment strategies for COVID-19. AAPS PharmSciTech 21(6):222. Published 2020 Aug 3. https://doi.org/10.1208/s12249-02001756-3

Publisher's Note Springer Nature remains neutral with regard to jurisdictional claims in published maps and institutional affiliations. 